\title{
A study on the effect of composition, and the mechanisms of recrystallisation in single crystal $\mathrm{Ni}$-based superalloys
}

\author{
Harshal N. Mathur ${ }^{1,2, a}$, Neil (C.N.) Jones ${ }^{3}$, and Catherine M.F. Rae ${ }^{2}$ \\ ${ }^{1}$ Institut für Metallkunde und Metallphysik, RWTH Aachen University, Aachen, Germany \\ ${ }^{2}$ Rolls-Royce UTP, Department of Materials Science \& Metallurgy, University of Cambridge, Cambridge, UK \\ ${ }^{3}$ Rolls-Royce plc, Derby, UK
}

\begin{abstract}
The effect of composition on recrystallisation of single crystal Ni-based superalloys was studied in a series of alloys that vary systematically in composition. Following room temperature macro-indentation and subsequent annealing, alloys containing higher Co concentration showed greater susceptibility to recrystallisation, and this has been attributed to the effect on the $\gamma^{\prime}$ solvus temperature and the stacking fault energy of the $\gamma$ phase. Mo, W and Ru did not appear to influence the recrystallisation behaviour systematically, although high concentration of all these elements led to the highest recrystallisation. Moreover, with grain orientation mapping, it was found that the nucleating recrystallisation grains form in orientations similar to the deformed regions, and subsequently twin to form higher angle boundaries and proliferate further within the deformed microstructure. The effects of the interaction between grain boundaries and secondary phases, such as the $\gamma^{\prime}$ and topologically close packed phases, were also studied.
\end{abstract}

\section{Introduction}

The plastic strains causing recrystallisation are induced by the difference in thermal contraction as the alloy directionally solidifies and cools within a ceramic mouldand-core system. If the plastic strains are above the critical level, the single crystal superalloy shows recrystallisation after the solution heat treatment; some examples are shown in Fig. 1. Casting strains are exacerbated by smaller component cross-sections and intricate designs, casting conditions and mould materials [1]. Incidental strains from post-casting processes, such as component machining, rough handling or surface cleaning, can also cause recrystallisation.

There is considerable evidence that grain boundaries, even at low density, are detrimental for the creep and fatigue properties of the alloy [2-4]. Recrystallisation accounts for a conservative $4 \%$ of the casting defects [5]. Since it occurs after the solution heat treatment, adding value to the casting, the scrap from recrystallisation is a significant cost to the investment casting industry.

Several aspects of recrystallisation in Ni-based superalloys have been studied, such as the effect of strain, deformation temperature, annealing conditions (for example [2-4,6-8]) and the interaction with secondary phases (for example [9-11]). There is, however, a lack of understanding for the effect of alloy composition on the recrystallisation of superalloys, and this is more so because the alloys vary in all alloying elements.

\footnotetext{
${ }^{a}$ Corresponding author: mathur@imm.rwth-aachen.de
}

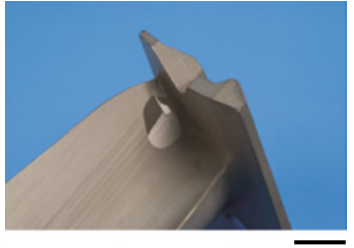

a)

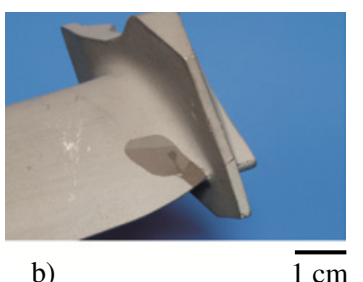

b)

$\overline{1 \mathrm{~cm}}$
Figure 1. Recrystallisation in single crystal turbine blades (Courtesy of Rolls-Royce plc).

In this work, single crystal Ni-based superalloys varying systematically in composition have been studied to examine the dependence of recrystallisation on composition. The mechanisms of nucleation and proliferation of recrystallisation have been studied using grain orientation maps. Moreover, the effect of the interaction between grain boundaries and secondary phases has been observed.

\section{Experimental}

Two "design of experiments" (DoE) series of single crystal superalloys that vary systematically in composition were used in this recrystallisation study. The LDSX alloys vary in $\mathrm{Co}, \mathrm{Mo}, \mathrm{W}$, and $\mathrm{Ru}$, and the UCSX 2 alloys vary in Ru only. These were provided in the heat treated condition by Rolls-Royce plc. CMSX 4 was also studied in the as-cast and fully heat treated conditions. The alloy compositions are given in Table 1.

Strain was induced by room temperature macroindentation along [001] on samples $2-3 \mathrm{~mm}$ in thickness. The indenter tool consisted of eight $1.5 \mathrm{~mm}$ diameter

This is an Open Access article distributed under the terms of the Creative Commons Attribution License 4.0, which permits unrestricted use, distribution, and reproduction in any medium, provided the original work is properly cited. 
Table 1. Nominal composition (weight \%) of the alloys studied; the systematically varying elemental additions are highlighted.

\begin{tabular}{|c|c|c|c|c|c|c|c|c|c|c|c|}
\hline & Al & Co & $\mathrm{Cr}$ & Mo & $\mathbf{W}$ & $\mathbf{R e}$ & Ta & $\mathbf{R u}$ & $\mathbf{T i}$ & Hf & $\mathbf{N i}$ \\
\hline UCSX 2-2Ru & \multirow{2}{*}{5.40} & \multirow{2}{*}{8.00} & \multirow{2}{*}{3.00} & \multirow{2}{*}{1.00} & \multirow{2}{*}{8.00} & \multirow{2}{*}{6.50} & \multirow{2}{*}{8.00} & 2.00 & \multirow{2}{*}{-} & \multirow{2}{*}{0.10} & \multirow{2}{*}{ Bal. } \\
\hline UCSX 2-5Ru & & & & & & & & 5.00 & & & \\
\hline & & & & & & & & & & & \\
\hline LDSX 1 & \multirow{8}{*}{6.00} & 3.00 & \multirow{8}{*}{3.00} & 2.50 & 2.90 & \multirow{8}{*}{6.20} & \multirow{8}{*}{6.50} & 3.50 & \multirow{8}{*}{0.25} & \multirow{8}{*}{0.10} & \multirow{8}{*}{ Bal. } \\
\hline LDSX 2 & & 8.00 & & 5.00 & 2.90 & & & 3.50 & & & \\
\hline LDSX 3 & & 3.00 & & 5.00 & 4.80 & & & 3.50 & & & \\
\hline LDSX 4 & & 8.00 & & 2.50 & 4.80 & & & 3.50 & & & \\
\hline LDSX 5 & & 8.00 & & 2.50 & 2.90 & & & 5.00 & & & \\
\hline LDSX 6 & & 3.00 & & 2.50 & 4.80 & & & 5.00 & & & \\
\hline LDSX 7 & & 3.00 & & 5.00 & 2.90 & & & 5.00 & & & \\
\hline LDSX 8 & & 8.00 & & 5.00 & 4.80 & & & 5.00 & & & \\
\hline CMSX 4 & 5.60 & 9.00 & 6.50 & 0.60 & 6.00 & 3.00 & 6.50 & - & 1.00 & 0.10 & Bal. \\
\hline
\end{tabular}

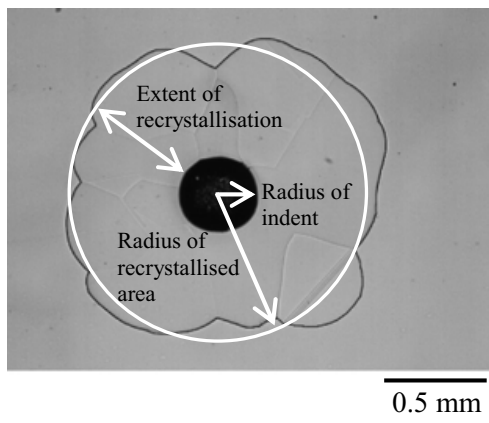

Figure 2. Measurement for extent of recrystallisation.

steel balls bearings, attached to a machined flat steel face with adhesive super-glue. A maximum compressive load of 19-20 kN was applied at $0.5 \mathrm{~mm} \mathrm{~min}^{-1}$ by standard mechanical testing equipment. It was ensured that the resultant strain fields between adjacent indents did not overlap.

The indented samples were subjected to isothermal heat treatments at $1280^{\circ} \mathrm{C}$ and $1335^{\circ} \mathrm{C}$ for $30 \mathrm{~min}, 4 \mathrm{hr}$ and $48 \mathrm{hr}$, with a ramp rate of $10^{\circ} \mathrm{C} \mathrm{min}^{-1}$; post-annealing, the samples were air-cooled.

The recrystallised samples were ground and polished for observation along [001] with the optical microscope. Using image analysis the individual recrystallisation areas were calculated. Subsequently, the distance of recrystallisation from the indent edge was calculated assuming circular recrystallisation structures; this is explained in Fig. 2. For comparison between alloys, the extents of recrystallisation were plotted against the indent radii.

Electron backscattered diffraction (EBSD) was used to obtain orientation maps. The samples were positioned at $70^{\circ}$ angle to the EBSD detector and scanned at $25 \mathrm{kV}$ with $1-4 \mu \mathrm{m}$ step size. All misorientations were studied using the angle-axis pair notation, and rotation angles of $5^{\circ}$ away from ideal coincidence site lattice (CSL) misorientations up to $\Sigma 29$ were considered. EBSD data has been shown as inverse pole figures (IPF) or local misorientation maps (kernel method, $11 \times 11$ pixel matrix). Electron imaging was done at $15 \mathrm{kV}$ at a working distance of $10-15 \mathrm{~mm}$.

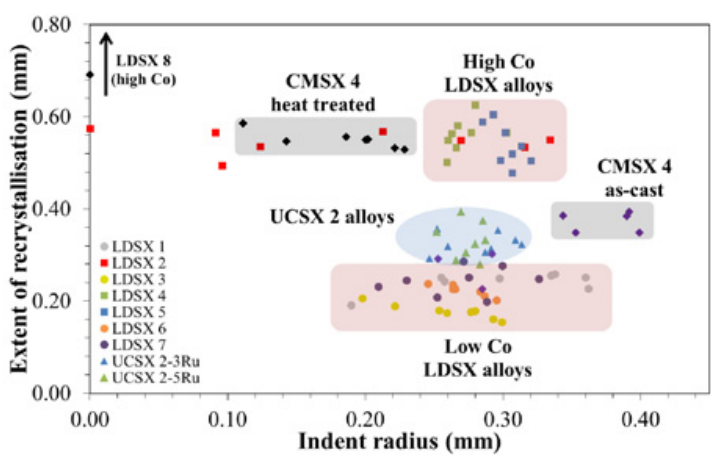

Figure 3. Extent of recrystallisation after $1280^{\circ} \mathrm{C} / 48 \mathrm{hr}$.

Differential scanning calorimetry (DSC) was used to determine the $\gamma^{\prime}$ solvus temperatures. The temperature program comprised heating at $20^{\circ} \mathrm{C} \mathrm{min}^{-1}$ to $1000^{\circ} \mathrm{C}$, and subsequently at $10^{\circ} \mathrm{C} \min ^{-1}$ to $1450{ }^{\circ} \mathrm{C}$ with a dwell of $10 \mathrm{~min}$. Experiments were carried out in a dynamic Ar environment.

\section{Results and discussion}

\subsection{Effect of composition}

The indented alloys were initially annealed at $1280{ }^{\circ} \mathrm{C}$ for $48 \mathrm{hr}$, and the extent of recrystallisation measured as described in Fig. 2, is plotted against indent radius for each alloy in Fig. 3.

The UCSX 2 alloys recrystallised to approximately the same extent. As this series varied only in the Ru content, the results show that $\mathrm{Ru}$ does not have a direct effect on the recrystallisation behaviour in this alloy series. It is known that $\mathrm{Ru}$ can reduce the stacking fault energy of the $\gamma$ phase [12], however its effect on the susceptibility to recrystallisation of Ni-based superalloys appears to be insignificant.

The most striking result was seen in the LDSX series, where the alloys were divided into two distinct groups. All the low recrystallisation $(0.15-0.3 \mathrm{~mm})$ alloys, LDSX 7, 1,6 and 3, contained the lower $3 \mathrm{wt} \% \mathrm{Co}$, whereas the $8 \mathrm{wt} \%$ Co alloys, LDSX 2, 4 and 5, all exhibited on average 2.5 times more recrystallisation $(0.5-0.6 \mathrm{~mm})$. From 


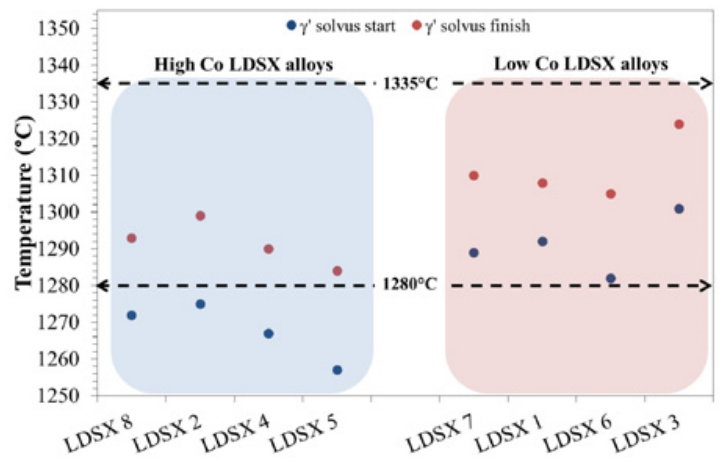

Figure 4. DSC measurements of $\gamma^{\prime}$ solvus temperatures.

Fig. 6 the difference in the recrystallisation microstructures is evident, where the low Co LDSX alloys have finer grains and higher grain densities. LDSX 8 was singular in that it showed such significant recrystallisation that adjacent indents impinged. As measurements following the protocol in Fig. 2 would underestimate the extent of recrystallisation, this alloy was not included in Fig. 3. Mo, $\mathrm{W}$ and $\mathrm{Ru}$ concentrations in the LDSX alloy series did not appear to have a systematic effect on recrystallisation, but there are some notable differences between the alloys. In particular LDSX 8, with the highest levels of all these elements, is extraordinarily sensitive.

The $\gamma^{\prime}$ solvus temperatures of all LDSX alloys were measured using the DSC. Since a sharp solvus temperature was not observed, the start and finish temperatures of $\gamma^{\prime}$ dissolution are shown in Fig. 4. At $1280^{\circ} \mathrm{C}$ the LDSX alloys are divided into two groups, where at $1280^{\circ} \mathrm{C}$ all the low Co LDSX alloys were below the $\gamma^{\prime}$ solvus, whereas all the high Co alloys were above the $\gamma^{\prime}$ solvus temperature.

In order to eliminate the effect of $\gamma^{\prime}$ on recrystallisation, four of the indented LDSX alloys were subjected to a further heat treatment at $1335^{\circ} \mathrm{C}$ for $4 \mathrm{hr}$, significantly above the $\gamma^{\prime}$ solvus temperatures. The extent of recrystallisation for two low Co alloys, LDSX 7 and 3 , and the two high Co alloys, LDSX 4 and 2, are shown in Fig. 3. In the absence of $\gamma^{\prime}$ even though the average recrystallisation in the low Co alloys more than doubled, the alloys remain divided in two separate groups. The difference in extent of recrystallisation was, however, much less than after the lower temperature anneal.

Figure 4 clearly shows that at the annealing temperature of $1280^{\circ} \mathrm{C}$ the Co composition divides the LDSX alloys in terms of the $\gamma^{\prime}$ solvus. As this phase impedes grain boundary migration and recrystallisation, it is consistent with the lower recrystallisation in the low Co alloys. This appears to be the primary effect of Co.

Betteridge [13] has shown in the Ni-Cr-(Al,Ti) system that at higher $\mathrm{Al}$ and $\mathrm{Ti}$ concentrations $\mathrm{Co}$ additions decrease the $\gamma^{\prime}$ solvus. Other studies on single crystal forms of Ni-based superalloys [14, 15], where the Co levels were modified systematically, clearly showed that the $\gamma^{\prime}$ solvus temperature increased by $>50^{\circ} \mathrm{C}$ by reducing Co by $10 \mathrm{wt} \%$. Co partitions more strongly to the $\gamma$ phase [16], consistent with high Co destabilising $\gamma^{\prime}$.

The decisive effect of Co on recrystallisation persisted even in the absence of the $\gamma^{\prime}$ phase (Fig. 3), indicating a

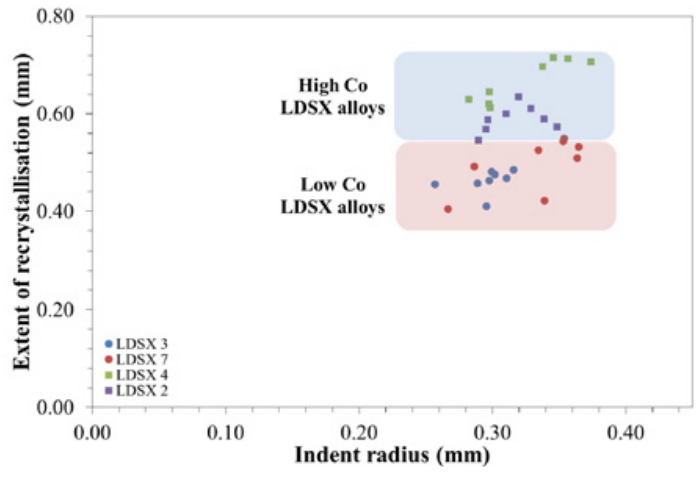

Figure 5. Extent of recrystallisation after $1335^{\circ} \mathrm{C} / 4 \mathrm{hr}$.

further effect of Co. It is known that Co additions reduce the stacking fault energy of Ni-alloys [17-19]. Higher stacking fault energy decreases the dissociation of dislocations into partials, aiding recovery by climb and cross-slip [17]. This would increase the formation rate of a cellular structure but lower the dislocation density and driving force for recrystallisation. In the absence of the $\gamma^{\prime}$ phase, a lower driving force would result in less recrystallisation. A lower stacking fault energy material would, hence, display more recrystallisation, consistent with the observations of this study.

\subsection{Mechanisms of recrystallisation}

\subsubsection{Proliferation}

Inverse pole figure (IPF) maps of the recrystallisation microstructures from representative high and low Co LDSX alloys after annealing at $1280{ }^{\circ} \mathrm{C}$ for $48 \mathrm{hr}$ are given in Fig. 6. The orientation of all grains were examined with respect to the surrounding grains. For all LDSX alloys, twin-related grains could be identified extending outwards from the indent edge; examples are highlighted in Figs. $6 \mathrm{~b}-\mathrm{c}$ and $6 \mathrm{e}-\mathrm{f}$. Due to sample sectioning effects some twin chains did not appear to initiate at the indent edge or terminate at the edge of the grain structure. Termination could also occur by occlusion by faster growing grains. Generally, 2-3 steps of twinning were observed.

The orientation of the outermost grains was also examined to ascertain whether the grains developed a preferred orientation during recrystallisation. Grain misorientation, with respect to the single crystal, are plotted for the high and low Co LDSX alloys in Fig. 7. Many of the grains were within $5^{\circ}$ of CSLs up to $\Sigma=29$, however, no dominant CSL boundary misorientations emerged during the later stages of recrystallisation. Most misorientations were between $35^{\circ}$ and $45^{\circ}$.

\subsubsection{Nucleation}

To determine the orientation of the nucleating grains the LDSX alloys were annealed briefly for $30 \mathrm{~min}$ at $1280^{\circ} \mathrm{C}$. The recrystallisation microstructures from representative low and high Co alloys are shown in Fig. 8. In the low Co alloy LDSX 3, Fig. 8d, fine grains had just initiated at the indent edge. Fig. $8 \mathrm{f}$ plots the lattice rotations between 


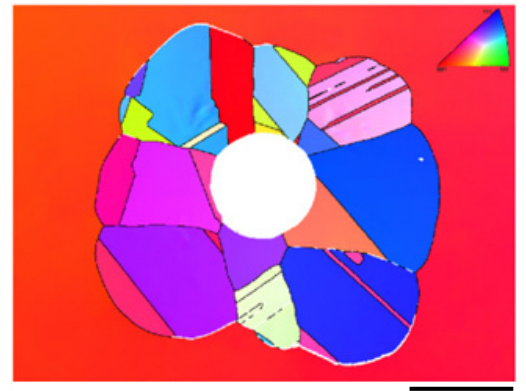

a)

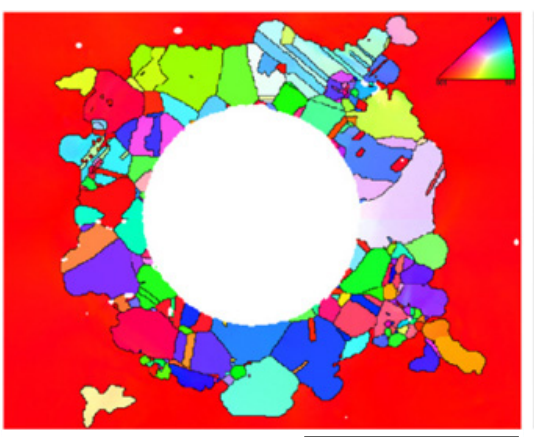

d)
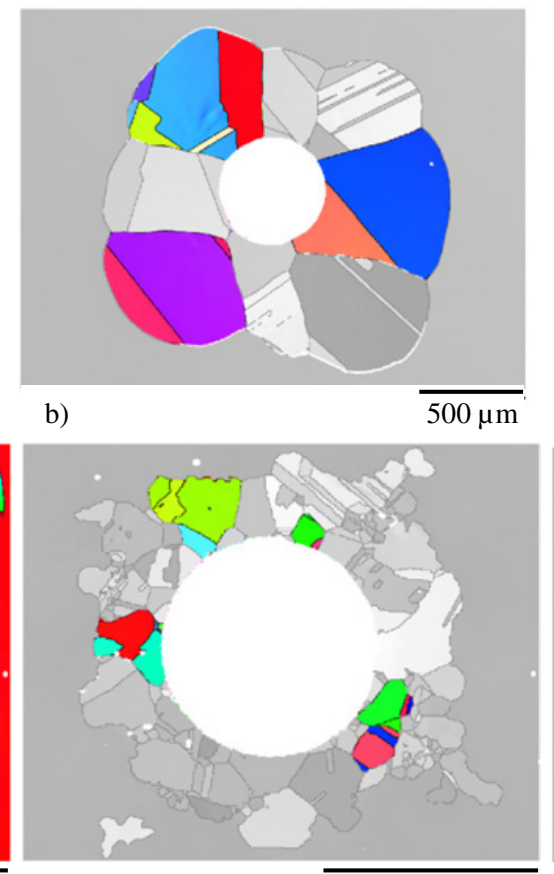

$500 \mu \mathrm{m}$
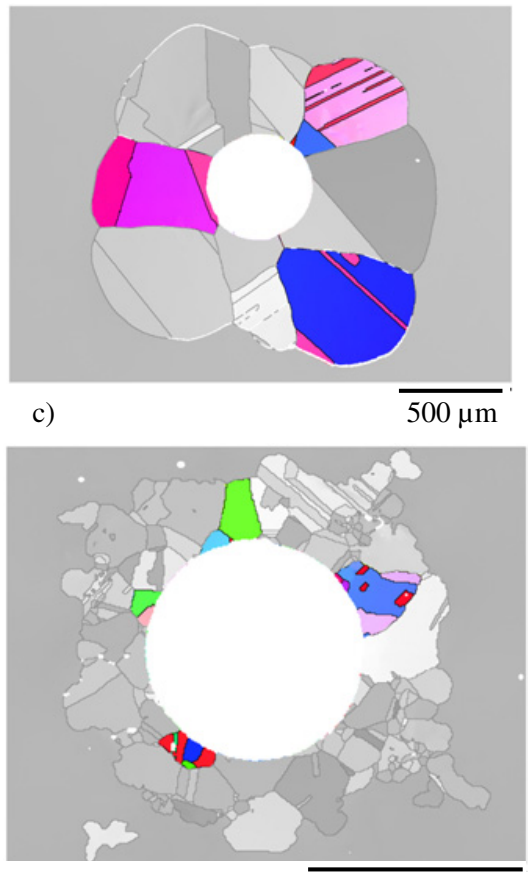

f)

$500 \mu \mathrm{m}$

Figure 6. EBSD-IPF maps of recrystallisation around indents: a-c) high Co (LDSX 4), and d-f) low Co (LDSX 3 ) alloys after $1280^{\circ} \mathrm{C} / 48$ hr; some selected twin chains are highlighted in $b-c)$ and $\mathrm{e}-\mathrm{f}$ ).

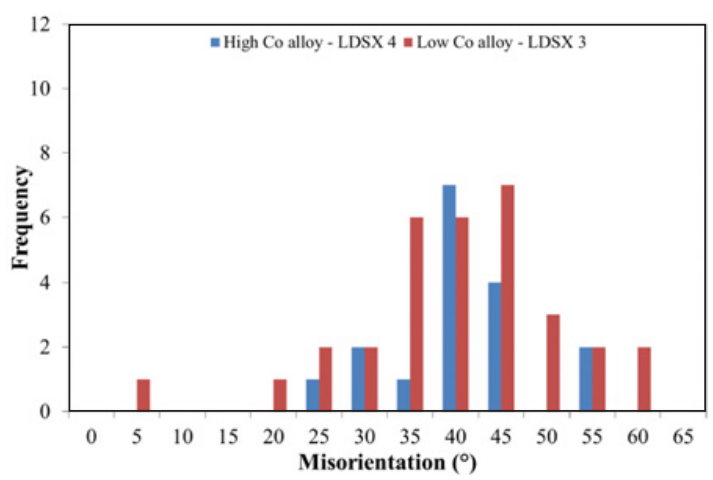

Figure 7. Angular misorientation $(\theta)$ distribution of the outermost grains in Fig. 6 with respect to the bulk single crystal.

adjacent pixels of the same indent at a lower magnification. This shows the small fraction of recrystallisation around the indent and quantifies the remnant plastic strain. In the high Co alloy, LDSX 4, Fig. 8a, recrystallisation was much more advanced, almost matching the $48 \mathrm{hr}$ anneal, indicating that the recrystallisation is much faster and limited by deformation in this alloy (cf. Fig. 6a).

Since recrystallisation was in the initial stages in LDSX 3, the misorientation of all the grains in Fig. 8d were measured with respect to the surrounding deformed region. As in the longer annealed microstructures, twin chains were found starting at the indent edge and some are highlighted in Fig. 8e. The misorientations of all grains are plotted in Fig. 9 to reveal a bimodal distribution. Distribution A is sharper and consists mainly of grains misorientated $20-30^{\circ}$ from the deformed matrix; distribution B shows a greater spread comprising of grains misorientated by $40-55^{\circ}$. More significantly, almost all grains in distribution $\mathrm{B}$ were twin related to grains in distribution A. A similar analysis of the high Co LDSX 4, Fig. 8a, was not possible because the recrystallisation had consumed the highly deformed region adjacent to the indent. Nevertheless, twin chains could be identified and some are highlighted in Figs. $8 \mathrm{~b}$ and c.

Interestingly, the lattice rotations induced straight after deformation at the indent edge were measured with up to $24^{\circ}$ misorientation, which is within the range of the recrystallised grains in distribution A. During annealing, deformed regions undergo recovery and are likely to form sub-grains with misorientations similar to the deformed matrix. These sub-grains change orientation by twinning in all alloys irrespective of composition. The four twin variants possible at each twining event leads to a larger spread in misorientations in distribution B of Fig. 9.

\subsection{Effect of secondary phases}

In Fig. 3 as-cast CMSX 4 showed lesser recrystallisation than the fully heat-treated alloy due to the presence of $\gamma^{\prime}$. The impeding effect of $\gamma^{\prime}$ on grain boundary migration has been widely reported, $[3,6,20]$, as the effect of carbides [10], nitrides and Laves phases [21]. Examination of the low Co alloys revealed that during the $1280^{\circ} \mathrm{C}$ anneal coarsened $\gamma^{\prime}$ particles act as pinning points to the migrating boundary, visible in the scalloped configuration of the recrystallising boundary, Fig. 10. Several coarsened $\gamma^{\prime}$ precipitates can be identified in Fig. 10a by their darker colour in this image. The orientation map of the same area, Fig. 10b, shows that those labelled A nearly preserve the orientation of the single crystal, and those labelled B are coherent with the recrystallising grain, and a very few are twin related to the matrix, labelled $\mathrm{C}^{*}$. The precipitates 


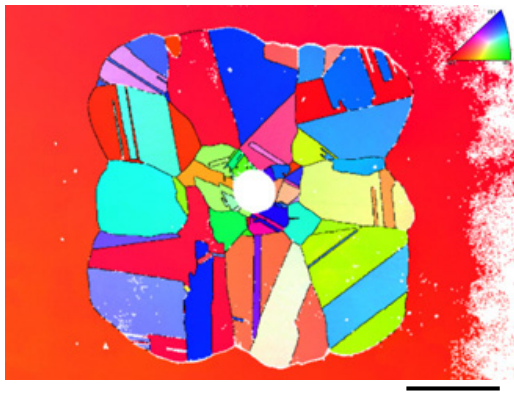

a)

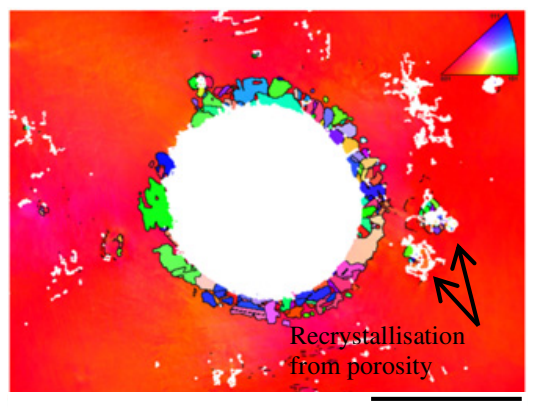

d)

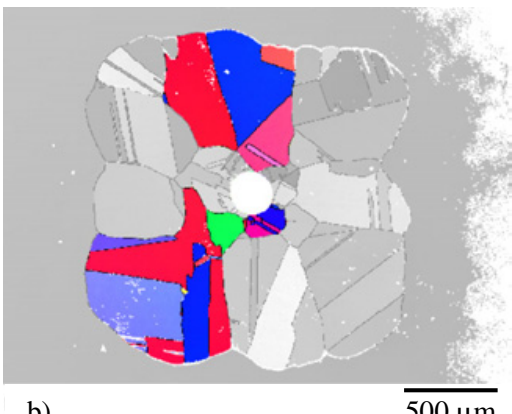

b)

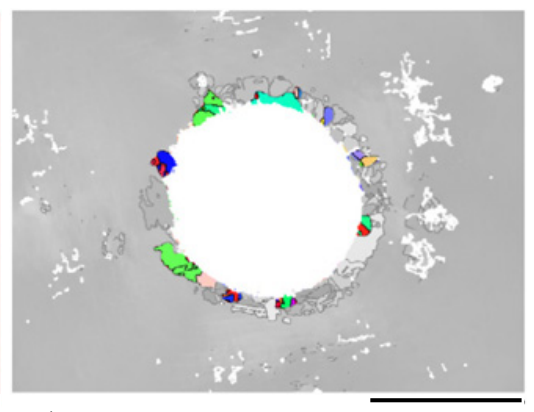

e)
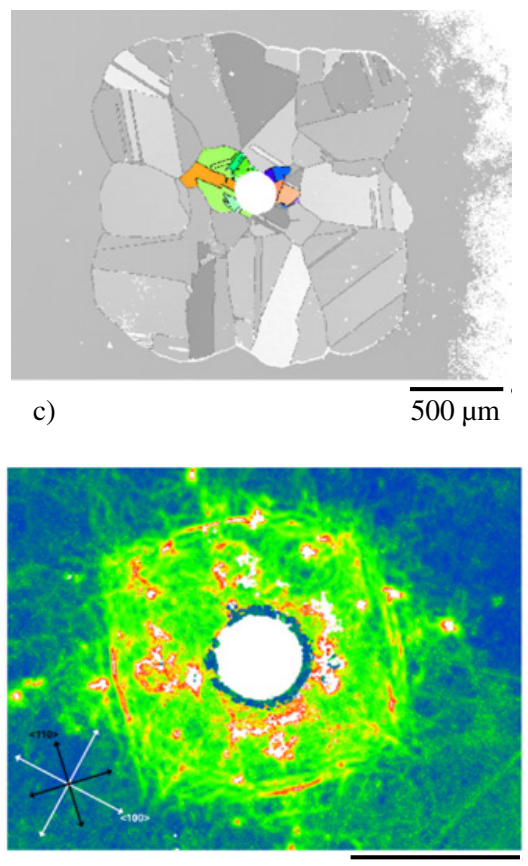

$500 \mu \mathrm{m}$

Figure 8. EBSD-IPF maps of recrystallisation around indents after $1280^{\circ} \mathrm{C} / 30 \mathrm{~min}$ : a-c) high Co (LDSX 4) and d-f) low Co (LDSX 3) alloys; f) local misorientation map of low Co alloy at low magnification (increasing misorientations from blue to red); some selected twin chains are highlighted in b-c) and e).

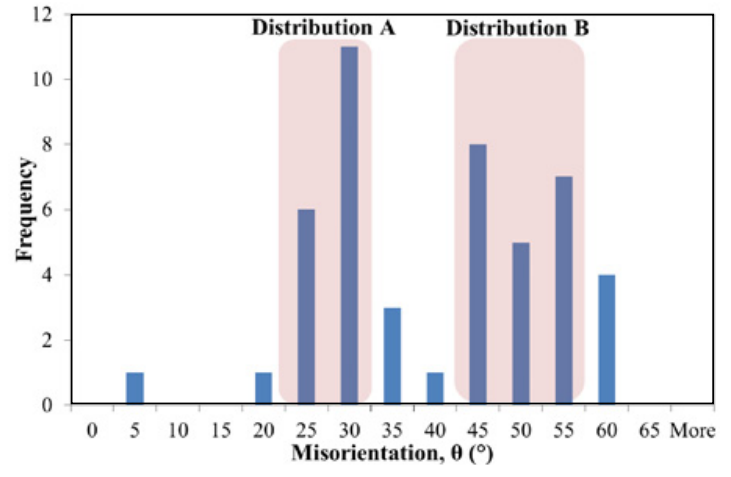

Figure 9. Angular misorientation $(\theta)$ distribution of grains in Fig. $8 \mathrm{~d}$ with respect to the surrounding deformed matrix.

A, show a gradual progression in orientation as they move away from the indent edge (see A*). Precipitate coarsening is facilitated by the more rapid diffusion in the boundary, and the slowing of the boundary due to diminishing driving force will enhance this effect as the boundary moves away from the indent edge. As the precipitates coarsen, the drag increases further exacerbating the effect. Similar results are seen in the work by Boothby et al. [21].

During recrystallisation below the $\gamma^{\prime}$ solvus, the precipitates B are discontinuously precipitated behind the moving boundary coherent with the growing grain, as previously reported $[3,11,21]$. These grain-precipitate interactions mostly occurred close to the edge of the recrystallised area, where the driving force for boundary migration is diminished.

Re-W rich TCP phases were also seen in LDSX 3 after the $1280{ }^{\circ} \mathrm{C}$ and $1335^{\circ} \mathrm{C}$ heat treatments. These always have an inhibiting effect on grain boundary
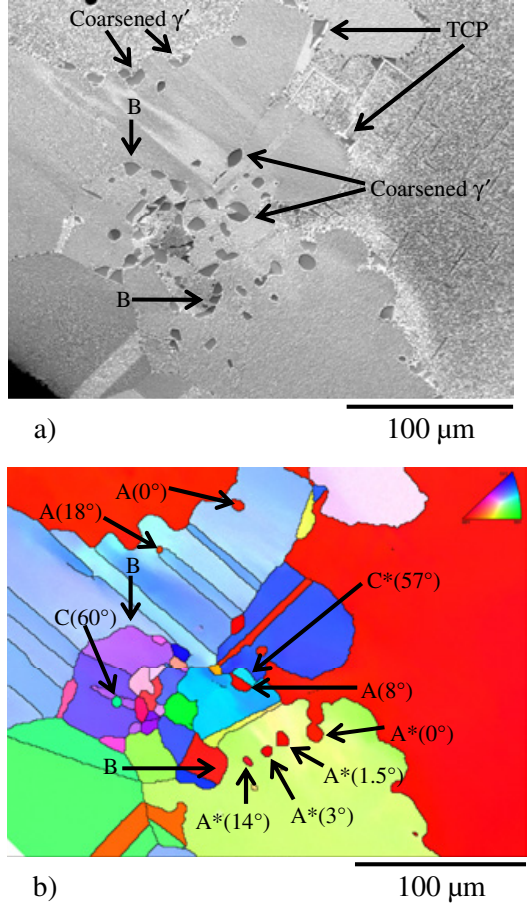

Figure 10. Coarsened $\gamma^{\prime}$ and corresponding EBSD-IPF map of the recrystallisation microstructure in low Co LDSX 3 alloy after $1280^{\circ} \mathrm{C} / 48 \mathrm{hr}$; angular misorientations are given in parentheses (reader referred to the text for explanation of labels).

motion, the boundaries migrating around the TCP phases destroying the orientation relationship and thus facilitating the change from needle-like to a globular morphology. Some examples are shown in Fig. 10a. 


\section{Conclusions}

- In a systematic DoE study, high Co alloys show a greater susceptibility to recrystallisation.

- Mo, W and Ru do not show a consistent effect, but high values of all three elements led to the highest amounts of recrystallisation.

- The primary effect of Co is to depress the $\gamma^{\prime}$ solvus, but a secondary effect is to decrease the stacking fault energy of the $\gamma$ phase, retarding dislocation recovery and increasing the driving force for grain migration.

- The recrystallisation nuclei have misorientations of $20-30^{\circ}$ with the deformed region, similar to the lattice rotations induced after indentation. The grains twin 2-3 times to form mobile higher angle grain boundaries.

- The $\gamma^{\prime}$ phase inhibits grain boundary migration, and interaction with grain boundaries can lead to coarsening and discontinuous precipitation of the $\gamma^{\prime}$ phase.

- TCP phases also hinder grain boundary migration.

Funding of a Dorothy Hodgkin Postgraduate Award and through the EPSRC-Rolls-Royce Strategic Partnership, EP/H022309/1 and EP/H500375/1, by the Engineering and Physical Sciences Research Council and Rolls-Royce plc is acknowledged.

\section{References}

[1] C. Panwisawas, H. Mathur, J.-C. Gebelin, D.C. Putman, C.M.F. Rae, R.C. Reed, Acta Mater 61, 51 (2013)w

[2] G. Xie, L. Wang, J. Zhang, L.H. Lou, Metall Mater Trans A 39A, 206 (2008)

[3] R. Burgel, P.D. Portella, J. Preuhs, Superalloys 2000 (TMS, Pennsylvania, 2000)
[4] U. Paul, P.R. Sahm, D. Goldschmidt, Mat Sci Eng A A173, 49 (1993)

[5] R.C. Reed, The Superalloys: Fundamentals and Applications, p 139 (Cambridge University Press, Cambridge, 2006)

[6] D.C. Cox, B. Roebuck, C.M.F. Rae, R.C. Reed, Mater Sci Tech 19, 440 (2003)

[7] G. Xie, L. Wang, J. Zhang, L.H. Lou, Scripta Mater 66, 378 (2012)

[8] J.J. Moverare, S. Johansson, R.C. Reed, Acta Mater 57, 2266 (2009)

[9] L. Wang, F. Pyczak, J. Zhang, R.F. Singer, Int J Mater Res 100, 1046 (2009)

[10] L. Wang, G. Xie, J. Zhang, L.H. Lou, Scripta Mater 55, 457 (2006)

[11] A.J. Porter, B. Ralph, J Mater Sci 16, 707 (1981)

[12] R.A. Hobbs, L. Zhang, C.M.F. Rae, S. Tin, Mat Sci Eng A 489, 65 (2008)

[13] W. Betteridge, Cobalt and its Alloys, p 74 (Horwood, Chichester, 1982)

[14] M.V. Nathal, L.J. Ebert, Metall Trans A 16A, 1849 (1985)

[15] R.N. Jarrett, J.K. Tien, Metall Trans A, 13A, 1021 (1982)

[16] R.A. Hobbs, R.A., S. Tin, C.M.F. Rae, Metall Mater Trans A 36A, 2761 (2005)

[17] F.J. Humphreys, M. Hatherly, Recrystallization and Related Annealing Phenomena, p 16, 23 (Pergamon, Oxford, 1996)

[18] J.R. Davis, ed. Nickel, Cobalt, and their Alloys, p 349 (ASM International, Ohio, 2007)

[19] D.A. Hughes, W.D. Nix, Mat Sci Eng A 122, 153 (1989)

[20] S.D. Bond, J.W. Martin, J Mater Sci 19, 3867 (1984)

[21] R.M. Boothby, G.B. Merrill, 7th Riso International Symposium - Recovery, Recrystallization and Grain Growth (Riso National Laboratory, Roskilde, 1986) 